\author{
ÁLVARO RECIO MIR \\ UNIVERSIDAD DE SEVILLA
}

\title{
Un nuevo arte en movimiento para la ostentación social: los primeros coches novohispanos y las ordenanzas del gremio de carroceros de la ciudad de México de 1706
}

$\mathrm{E}$ N El Ámbito de los Coches de Caballos, el siglo XViII supuso el liderazgo de Francia e Inglaterra en la construcción de vehículos de carácter artístico y su definitiva expansión mundial. La influencia de ambas y el surgimiento de sus imperios coloniales permitieron que los carruajes construidos en ellas ruaran por toda la tierra. ${ }^{\mathrm{I}}$

No obstante, como seguro precedente a tal realidad, hay que referir el papel de España en esa evolución. Casi nada se sabía hasta ahora al respecto, aunque se había apuntado la importancia que tuvieron sus caballos. ${ }^{2}$ Sin embargo, todo hace suponer que Castilla debió ser pionera en la universalización de los carruajes al difundirlos en los virreinatos americanos a la vez que tal fenómeno ocurría en Europa. Incluso algunas ciudades americanas se adelantaron a las españolas y europeas en la construcción de coches. Prueba de ello fue la creación del gremio de carroceros de la ciudad de México en I706, cuando también se aprobaron sus primeras ordenanzas.

I. Véanse Daniel Roche (dir.), Voitures, chevaux et attelages du XVIe au XIXe siècle, París, Art Équestre de Versailles, 2000; Historia del carruaje en España, Madrid, Fomento de Construcciones y Contratas, 2005, pp. I80 y ss.; Andres Furger, Driving. The Horse, the Man and the Carriage from 1700 up to the Present Day, Hildesheim, Georg Olms Verlag, 2009, pp. 5 I y ss., y Pomp and Power. Carriages as Status Symbols, Museo de Londres, en prensa.

2. Furger, op. cit., pp. I 45-I 47 . 
Precedentes de la carrocería novohispana: la carretería y los primeros coches

Las alusiones con que hasta ahora contamos, fundamentalmente literarias, parecen probar que el uso de coches en el virreinato de la Nueva Espańa se produjo de manera paralela a lo ocurrido en España y en Europa en general. Tan conocidas como expresivas son las referencias de Bernardo de Balbuena, que en I604, en su Grandeza mexicana, aludía ya a "coches, carrozas, sillas y literas". El habitual tono laudatorio de las fuentes virreinales parece probar que el lujo más exacerbado fue consustancial a su carrocería y que tal suntuosidad alcanzó cotas superlativas en arneses y uniformes, como se deduce de la fuente referida, que también menciona "ricos jaeces de libreas costosas/ de aljófar, perlas, oro y pedrería/ son en sus plazas ordinarias cosas". ${ }^{3}$

Por su parte, Thomas Gage dijo de los coches mexicanos de 1626:

son más caros que los de la Corte de Madrid y de cualquier otra parte de la Cristiandad, porque allí no faltaban ni plata, ni oro, ni piedras preciosas, ni paños dorados, ni tampoco las mejores sedas traídas de la China, para enriquecer estos carruajes, incluso a sus magníficos caballos les colocaban costosas bridas y herraduras de plata. ${ }^{4}$

También resulta significativo que ya en I 549 hubiese en la ciudad de México un gremio de guarnicioneros de sillas y aderezos de caballos, 5 el cual se relacionaría más tarde con la construcción de coches. La confluencia de distintos profesionales en la actividad carrocera fue, además de particularidad de estos objetos de clara significación artística, ${ }^{6}$ una de las causas de la creación de un gremio propio.

3. Bernardo de Balbuena, Grandeza mexicana, México, Universidad Nacional Autónoma de México, 2008, p. 22.

4. Thomas Gage, Viajes por la Nueva España y Guatemala, Dionisia Tejera (ed.), Madrid, Historia 16, 1987, p. 165. Véanse otras citas en las pp. 172-173 y 194 y otras fuentes en Ramón María Serrera, Tráfico terrestre y red vial en las Indias españolas, Madrid, Dirección General de Tráfico, I993, p. 314.

5. Sus ordenanzas aparecen transcritas en Francisco del Barrio Lorenzot, Ordenanzas de gremios de la Nueva España, México, Secretaría de Gobernación, I920, pp. 8-10.

6. Este carácter artístico se trata en Álvaro Recio Mir, "¿Qué Indias hay donde no hay coches? Notas sobre el carruaje como objeto de análisis histórico-artístico en España y América”, en Montserrat Galí Boadella (coord.), Avances y perspectivas. Coloquio Internacional del Arte en Puebla, Puebla de los Ángeles, Benemérita Universidad Autónoma de Puebla, en prensa. 
En cualquier caso, sobre el origen de la carrocería novohispana resulta capital la real cédula de Felipe II del 24 de noviembre de 1574, que afirmaba que en la "Nueva España [...] se han comenzado a usar y usan andar en coches y carrozas muchas gentes y que eso va cada día creciendo", por lo que disponía que "ninguna persona pueda pasar coche ni carroza alguna a las dichas nuestras Indias, ni las hacer, ni labrar en ellas"?

Tres son las cuestiones, en relación con los orígenes de los coches novohispanos, que evidencia esta norma. La primera, que su uso ya era habitual en la temprana fecha de I574. La segunda, un comercio de coches que, como todo el americano, pasaba por el puerto hispalense. Aún carecemos de datos sobre esta exportación, pero cabe intuir que Sevilla pudo desempeñar también un papel significativo en ella. ${ }^{8}$ En tercer lugar, la norma prueba la construcción de coches en América y el origen temprano de su carrocería. No obstante, no sabemos el efecto que produjo tal disposición en el ámbito novohispano, ya que la titubeante política de la Casa de Austria sobre el uso de coches no permite sacar conclusiones definitivas al respecto. $9^{9}$ Empero, el Consejo de Indias preguntó al virrey Luis de Velasco el Joven en I59I si convenía que volvieran a ruar coches en la Nueva España, a lo que contestó afirmativamente, aunque no sabemos si así ocurrió. ${ }^{10}$

En cualquier caso, la generalización del uso de coches que parece deducirse de las fuentes literarias e iconográficas invita a pensar que la ciudad de México pudo convertirse en un importante centro carrocero que abastecería de vehículos, además de a su cada vez mayor población, al amplísimo virreinato del que era orgullosa capital. ${ }^{\text {I }}$

7. Esta fuente la tomamos de Serrera, op. cit., pp. 293 y 294.

8. Sobre la producción de coches en la Sevilla de entonces, remitimos a Álvaro Recio Mir, "Los maestros de hacer coches y su pugna con los pintores: un apunte sevillano de la dialéctica gremio-academia”, Laboratorio de Arte, núm. I8, 2005, pp. 355-369, en especial las pp. 356-365.

9. Esencial sobre tal política resulta Alejandro López Álvarez, Poder, lujo y conflicto en la Corte de los Austrias. Coches, carrozas y sillas de mano, I550-I700, Madrid, Polifemo, 2007.

ıo. Véase Alejandro López Álvarez, "Los vehículos representativos en la configuración de la corte virreinal: México y Lima, I590-I700”, en Enrique García de Santo Tomás (dir.), Materia crítica. Formas de ocio y de consumo en la cultura áurea, Madrid, Universidad de Navarra, 2009, p. 27 I.

I I. Por ejemplo, el citado Gage decía al respecto: "en México había más de quince mil carruajes". Aunque a todas luces resulta una cifra exagerada, la creemos indicativa de un progresivo aumento en el número de coches. Véase Gage, op. cit., p. I65. Por su parte, Lionnel Waffer, a finales de ese siglo xvir decía que en la ciudad de México había 4000 coches, lo que parece una cifra más verosímil. Véase Serrera, op. cit., pp. 293 y 294. 


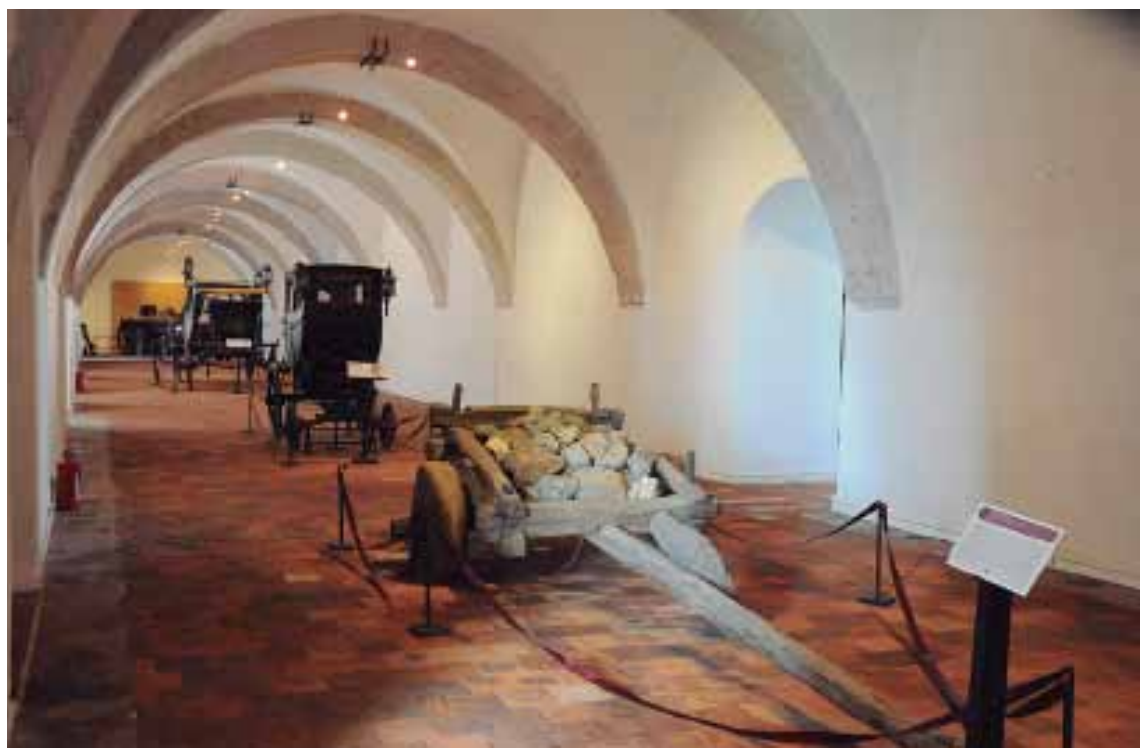

I. Carreta de minas, siglo xix. Museo Regional de Guadalupe, Zacatecas. Foto: Museo Regional de Guadalupe, Zacatecas. Conaculta-INAH-MÉx. "Reproducción autorizada por el Instituto Nacional de Antropología e Historia”.

Contamos con datos sobre los antecedentes de tal actividad en Puebla de los Ángeles. Una recopilación documental del siglo xvin recoge normas de los virreyes Antonio de Mendoza y Luis de Velasco sobre las "personas que hacen en esta ciudad carretas" y los "oficiales de carpinteros [...] que labran y tratan en carretas". ${ }^{\text {I2 }}$

No se pueden confundir estos carros con los coches. Los carros, cuyos orígenes se remontan a las civilizaciones de la Antigüedad — china, egipcia y mesopotámica一, son antecedentes evidentes de los coches. Estos últimos, en cambio, surgieron en Europa en los albores del Renacimiento y su diferencia técnica fundamental radica en que los coches, a pesar de tener una estructura similar a la de los carros, sumaron un sistema de amortiguación entre sus cajas y los ejes de sus ruedas que los hacía más confortables. ${ }^{\mathrm{I} 3}$ Como apuntaremos en adelante, fueron los carpinteros especializados en la construcción de carros los que, en el siglo Xvi, constuyeron los primeros coches (figs. I y 2).

I2. Archivo General Municipal de Puebla (en adelante Agmp), Archivo Histórico, Legislación, Reales Cédulas, vol. 9, ff. 2 Iv y 6ov.

13. Acerca de esta cuestión esencial remitimos a Historia del carruaje en España, op. cit. 
2. Carreta, L'Encyclopédie de Diderot y D'Alambert,

París, s.e., I75I-I772. ARTFL.

Encyclopédie Proyect, University of Chicago.
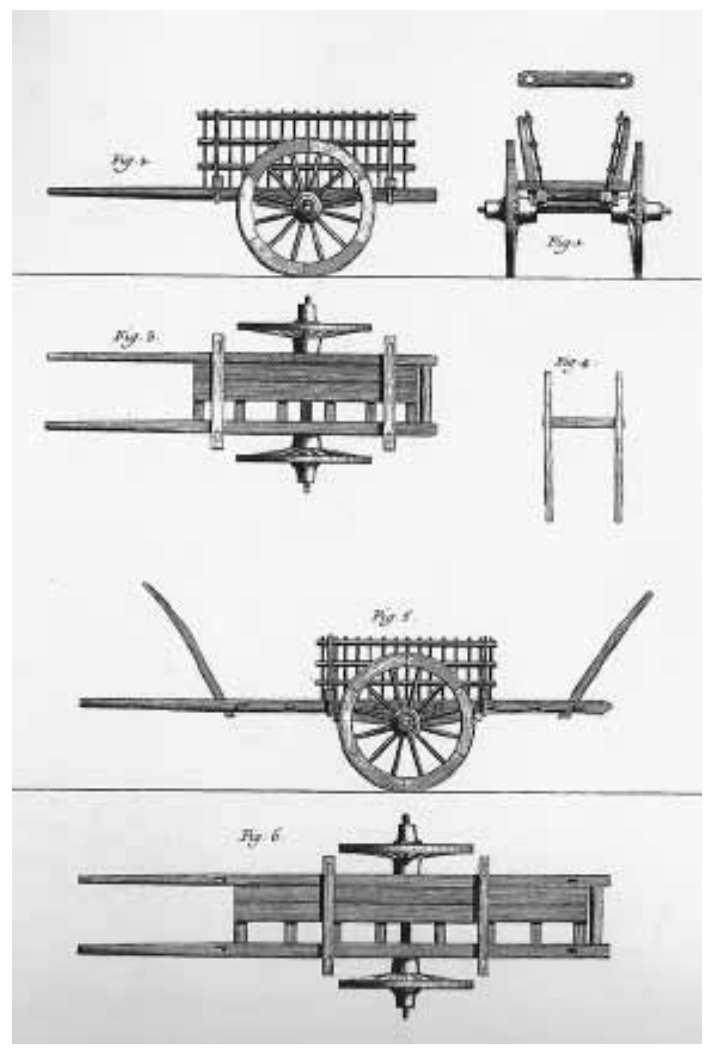

Pese a que la tradición afirma que el beato Sebastián de Aparicio fue quien introdujo los carros en la Nueva Espańa, su presencia hay que atribuirla a Hernán Cortés, ya que en agosto de I519, antes de iniciar su viaje a Tenochtitlán, encargó unas carretillas para cargar cañones al carpintero Diego Hernández. Éstos debieron de ser, según Hugh Thomas, los primeros vehículos con ruedas de América, cuyas culturas apenas tenían antecedentes al respecto. Poco más tarde, durante la conquista de México, parece que los carros desempeñaron un papel significativo. De igual modo, cuando Cortés decidió reconstruir la ciudad, las carretillas volvieron a ser esenciales. ${ }^{\mathrm{I}}$

I4. Véase Hugh Thomas, La conquista de México. El encuentro de dos mundos, el choque de dos imperios, Barcelona, Planeta, 2007, pp. 3I8, 43 I y 753. Sobre los hipotéticos antecedentes prehispánicos de los carros, cabe mencionar al menos las figurillas de barro, particularmente 
Otra prueba de que Cortés fue el fundador de la carretería novohispana se encuentra en el proceso iniciado en I53 I contra Juan Ortiz y Diego Delgadillo, en el cual se dijo que los frailes del convento de Santo Domingo habían empleado una carreta, aclarando un testigo del juicio que con anterioridad a ésta sólo había existido en la ciudad "una de don Hernando". En cualquier caso, su uso debió generalizarse pronto, ya que un acta de cabildo de la ciudad de México, fechada en I540, obligaba a "los que traigan carretas vayan a pie delante de ellas". ${ }^{5}$ " Normas semejantes se dictaron en Puebla, lo que evidencia los primeros problemas de circulación. ${ }^{\mathrm{I}}{ }^{6}$

Precisamente en Puebla desarrollaba entonces su actividad misional el referido Sebastián de Aparicio, caracterizada por usar carretas "gallegas" construidas por el carpintero Miguel Casado. Al morir en I600, tal actividad cobró relieve al plantearse su canonización. Así, el obispo de Tlaxcala indicó a Felipe III que Aparicio “trabajaba con unas carretas”. De igual modo, el superior del convento franciscano de Puebla certificó su extrema humildad al dormir "en el corral donde traía sus carretas". ${ }^{17}$

La fuente que trata esta actividad más extensamente es la biografía del beato que publicó en I769 José Manuel Rodríguez, quien señaló que, una vez en la Nueva España, Sebastián de Aparicio pasó de Veracruz a Puebla, donde

arbitró el modo de formar carretas, a que uncidos los novillos, ya bueyes mansos, completó el todo de la utilísima máquina, ignorada también hasta entonces en el país, con que se comenzaron a transportar las semillas de las haciendas de campo y mercaderías que desembarcaban en el puerto de Veracruz a las ciudades de Puebla y México. ${ }^{18}$

de la región del golfo de México, que cuentan con ruedas. De igual manera, las andas en que se transportaba a los emperadores aztecas podrían quizá ser entendidas como antecedentes de las sillas de mano.

15. Marita Martínez del Río de Redo, "El transporte en la historia de México", Artes de México, primera época, núm. 197, 1960, pp. 31-32. Iguales normas se dieron a la vez en Lima: véase Guillermo Lohmann Villena, "De coches, carrozas y calesas en Lima en el siglo xviI: una aproximación", Revista del Archivo General de la Nación, núm. I4, 1996, pp. II II57, en especial la p. II3.

I6. Agmp, Archivo Histórico, Legislación, Reales Cédulas, vol. 9, ff. 40v y 66v.

17. Leobardo García, Pionero, el beato Sebastián de Aparicio, Puebla, Nueva Edición, 2004, pp. 19-23.

I8. José Manuel Rodríguez, Vida prodigiosa del V. Siervo de Dios Fray Sebastián de Aparicio, religioso lego de la regular observancia de N.S.P. San Francisco e hijo de la provincia del 
3. Sebastián de Aparicio, "el de las carreteras", tomado de Vida prodigiosa del venerable siervo de Dios..., op. cit. (vid supra n. I8), p. I04.

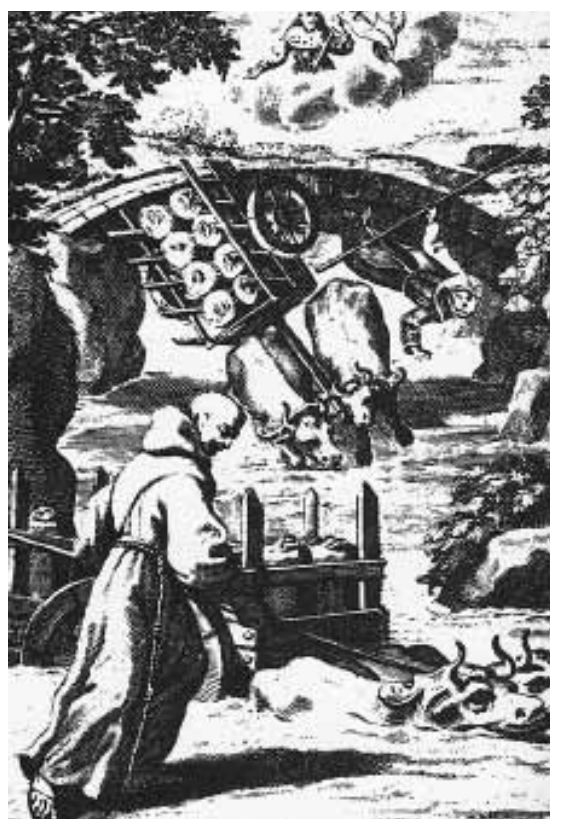

La misma fuente continúa diciendo que Aparicio pasó de Puebla a México "aplicando desde aquí su singular industria, sin perdonar trabajo ni fatiga a descubrir camino proporcionado para el tránsito cómodo de las carretas dichas, abrió el que en el día se usa de esta ciudad al célebre Real de Minas de Zacatecas”. Estas carretas no sólo tuvieron carácter utilitario, ya que fueron también en "este Nuevo Mundo un eremitorio volante en cada una de aquellas en el mismo venerable se conducía” (fig. 3). ${ }^{19}$

De tan expresiva fuente cabe resaltar, en primer lugar, el protagonismo del beato, quizá más que en la introducción de la carretería en México, en su difusión. De igual modo, resulta evidente la originaria función utilitaria de sus carretas, lógicamente asociadas al transporte de mercancías por las rutas comerciales novohispanas. Pero quizá lo más interesante sea la interpretación sagrada que se dio a las mismas, llamadas eremitorios volantes, y así convertidas, además de en medio de liberar a los indios tamemes de acarrear sus car-

Santo Evangelio de México, México, Imprenta de Felipe de Zúñiga y Ovando, I769, pp. I6-I8. Agradezco la referencia de tan importante fuente a nuestro colega poblano Fabián Valdivia. 19. Idem. 
gas, en una forma de evangelización, en instrumento de salvación. Se daba así un origen mítico-religioso a la carretería novohispana.

No es de extrañar que las carretas fuesen el distintivo de Aparicio, al cual se le conoce como "el de las carretas". Ello se reflejó en su iconografía, como se ve en la capilla del convento franciscano de Puebla donde reposa su cuerpo. El ciclo pictórico que allí relata su vida, ejecutado en parte por Miguel Jerónimo Zendejas a inicios del siglo XIX, destaca el carácter milagroso con que conducía sus vehículos. Así, los textos que acompañan tales pinturas señalan: "Ya en el giro tus carros tan gustoso/ caminas Aparicio con anhelo/ de ser a tu convento provechoso,/ que tu andar no parece sino vuelo!”. Incluso mediante los carros recibió el favor de san Francisco de Asís, de lo que trata una imagen del ciclo poblano que especifica: “¿Cómo es eso Aparicio? Que cargado/ así camine el carro sin el ege/ más que me admira? Si tu Padre amado/ como a un hijo querido te protege!/ Francisco es quien la rueda ha sustentado". ${ }^{20}$

Las carretas que difundió a partir de 1535 Sebastián de Aparicio en la Nueva España son llamadas por las fuentes "gallegas", quizá por la región de origen del personaje. Sobre este tipo, Ramón Serrera señala que debió de tratarse del habitual en Castilla en esa época. ${ }^{21}$ En concreto, creemos que pudo ser el tipo llamado "galera". 22

No faltan otros posibles introductores de la carretería en la Nueva España, ya que el padre Pascual Carrasco se arrogaba en I575 haber sido "el primer inventor de carros", con los que "abrió el camino de Zacatecas y de otras minas más adelante, y el primero que con ellos fue a Veracruz". Es posible que ello no contradiga lo antes señalado si distinguimos los carros de Carrasco de las carretas de Aparicio y de las carretillas de Cortés. Aunque similares, los carros eran mayores, por lo que solían ser tirados por dos yuntas de bueyes, mientras que las carretas, menores, lo eran por una. ${ }^{23}$

20. Sobre estas pinturas, las poesías citadas y el propio Aparicio, véase Pedro Ángeles Jiménez, "Fray Sebastián de Aparicio. Hagiografía e historia, vida e imagen", en Los pinceles de la historia. El origen del reino de la Nueva España, I680-I750, México, Universidad Nacional Autónoma de México-Instituto de Investigaciones Estéticas/Museo Nacional de Arte, I999, pp. 247-259.

21. Serrera, op. cit., pp. 235 y ss.

22. Véase sobre tal tipo Teresa Andrada-Vanderwilde et al., Museo de Carruajes, Sevilla, Real Club de Enganches de Andalucía, 2004, pp. 72 y 73.

23. Aunque no es nuestra intención en este caso abordar la tipología carretera, véanse al menos Secundino Gutiérrez Álvarez, Las comunicaciones en América: de la senda primitiva al ferrocarril, Madrid, Mapfre, I993, pp. I07 y I08; y Serrera, op. cit., pp. 235 y ss. 
En cualquier caso, a mediados del siglo XVI empezaron a despuntar algunos centros carreteros. Las fuentes aluden tanto a Querétaro y San Miguel el Grande — hoy de Allende-, estratégicamente ubicadas entre la capital y Zacatecas, ${ }^{24}$ como a las remotas localidades de Tlaltenango y Juchipila, ya en el xvir y en el entorno zacatecano. ${ }^{25}$

La generalización de los carros se reflejó en las Ordenanzas de descubrimiento, nueva población y pacificación de las Indias, publicadas en 1573 por Felipe II, en las que, en relación con la ubicación de las ciudades de nueva fundación, se dictaba que no fuera en lugares muy altos al complicar su "acarreto" y abastecimiento. $^{26}$

Sobre la ciudad de México, la contemporánea Relación geográfica de su arzobispado, al referirse a Cuernavaca, alude a que la producción del ingenio azucarero allí existente era transportada no por recuas de mulas, sino por carros. ${ }^{27}$ A finales de dicho siglo eran ya numerosas las normas que regulaban el uso de tales vehículos. ${ }^{28}$

De nuevo puede ser aludida la Grandeza mexicana de Balbuena, que al describir la actividad de la ciudad de México dice: "Recuas, carros, carretas, carretones, / de plata, oro, riquezas, bastimentos/ cargados salen, y entran a montones". ${ }^{29}$

No obstante y como indicamos, pronto se hicieron, además de carros, coches. Su éxito radicó en el carácter representativo que alcanzaron, por lo que de inmediato los usaron las más altas instancias sociales del virreinato. Así, al virrey marqués de Montes Claros, cuando llegó a Veracruz en I603, le esperaban los coches y las literas de su antecesor, el conde de Monterrey. Sin embargo, lo más interesante es que unas advertencias anónimas sobre el buen

24. Gutiérrez Álvarez, op. cit., p. Io6.

25. Thomas Calvo, Por los caminos de Nueva Galicia: transportes y transportistas en el siglo XVII, Universidad de Guadalajara (México), I997, p. 36.

26. También aluden a la "comodidad de acarretos [de] entrada y salida". Véase El orden que se ha de tener en descubrir y poblar. Transcripción de las ordenanzas de descubrimiento, nueva población y pacificación de las Indias dadas por Felipe II el 13 de julio de 1573 en el Bosque de Segovia según el original que se conserva en el Archivo General de Indias, Madrid, Ministerio de la Vivienda, 1973, pp. 38 y 84.

27. José Miguel Morales Folguera, La construcción de la utopía. El proyecto de Felipe II (1556-1598) para Hispanoamérica, Universidad de Málaga, 200I, p. I55.

28. Barrio Lorenzot, op. cit., pp. 267 y ss.; "Índice del ramo de ordenanzas", Boletín del Archivo General de la Nación, t. XI, núm. 3, 1940, pp. 535-557, y Silvio Zavala, Ordenanzas del trabajo. Siglos XVI y XVII, México, Elede, 1947, pp. 235 y ss.

29. Balbuena, op. cit., p. 7. 


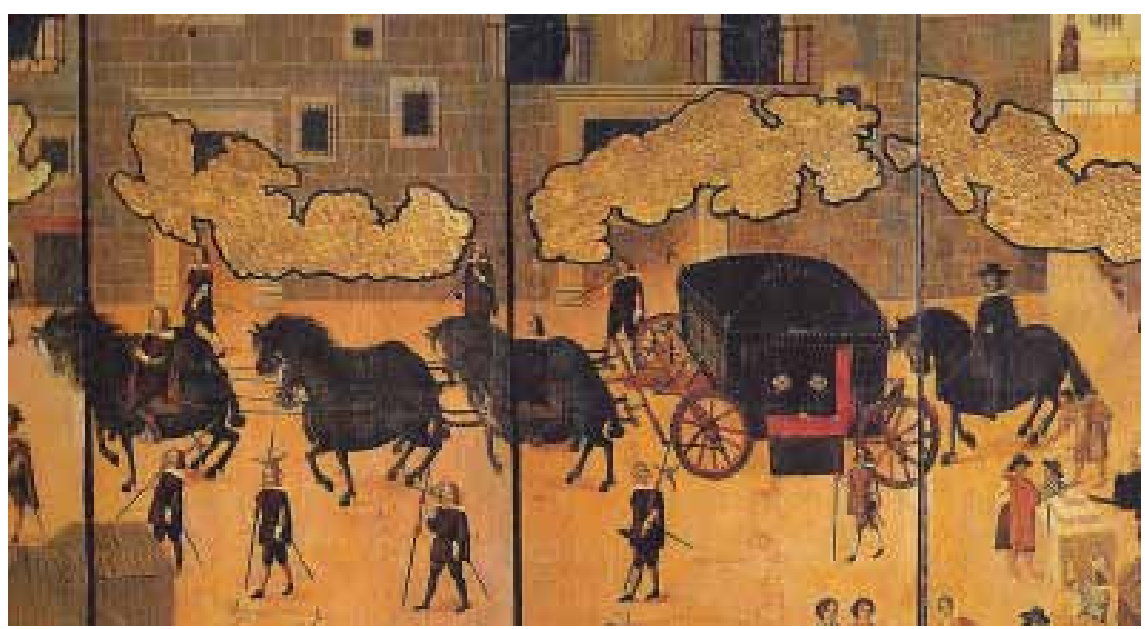

4. Anónimo, carroza virreinal, siglo xviı, óleo sobre lienzo, biombo del Palacio de los virreyes de México. Museo de América de Madrid.

gobierno virreinal recomendaban a Montes Claros contar con cuatro coches: uno para él, otro para la virreina y dos para sus criados. ${ }^{30}$

En España, la institucionalización del coche se produjo en el reinado de Felipe III. ${ }^{3 \mathrm{I}}$ En América, prueba de ello fue el empleo de coches en las entradas virreinales. En México fue el marqués de Villena el que lo usó por vez primera en 1640,32 mientras que en Perú el marqués de Mancera fue el primer virrey que, en I639, entró en coche a Lima, vehículo que le había regalado el cabildo de la ciudad. Los demás virreyes de Perú siguieron tal modelo, resultando significativo que fuesen agasajados con un caballo, recuerdo de la tra-

30. Guillermo Porras Muñoz, "Viaje a Méjico del marqués de Montes Claros y advertencias para su gobierno", Revista de Indias, núm. 8, 1947, pp. I I7-I26. Agradezco a mi discípulo Alejandro Wang Romero el haberme facilitado esta referencia bibliográfica.

3I. Véase Alejandro López Álvarez, "El nuevo cortesano barroco: la institucionalización del coche y las licencias para su uso (el caso de Murcia, I6I I-I62I)", en Enrique Soria Mesa y Juan J. Bravo Caro (eds.), Las elites en la época moderna: la monarquía española, Universidad de Córdoba (Espańa), 2009, t. IV, pp. 269-279.

32. José Miguel Morales Folguera, Cultura simbólica y arte efimero en Nueva España, Granada, Junta de Andalucía, I99 I, p. I09. 
dición medieval caballeresca, y a la vez con una carroza, obra de talleres locales y símbolo del ideal cortesano del mundo moderno (fig. 4). ${ }^{33}$

Sin duda, el uso habitual por los virreyes de coches de caballos fue reflejo de una realidad previa, que no haría más que aumentar a partir de mediados del siglo XVII. ${ }^{34}$ Ello, sin duda, se debió al carácter de símbolo de estatus que alcanzaron, ya que estas nuevas obras de arte rodante permitían a su ocupante mostrar su privilegiada condición social. Los coches se convirtieron así en una suerte de púlpitos desde los cuales se proclamaba cierta superioridad — no sólo física - sobre el resto de la sociedad. Esto, que también ocurrió en Europa, cobró en la Nueva España una significación especial, lo que explica la extrema suntuosidad de sus carruajes, ya que el lujo se convirtió en una obsesión para la sociedad virreinal. Serrera ha explicado que, debido a que en América las diferencias en los niveles superiores de la sociedad eran menos rígidas que en la metrópoli, lo suntuario se convirtió, aún más que en España, en elemento definidor de la condición social, en "mecanismo exteriorizador del status personal y familiar". ${ }^{35}$ Así, en una sociedad cortesana como la barroca, en la que primó la apariencia, el coche se hizo imprescindible y, como dice Gustavo Curiel, extensión del lujo de las casas (fig. 5). ${ }^{36}$

33. Véanse Lohmann Villena, op. cit., pp. I25 y ss., y Rafael Ramos Sosa, Arte festivo en Lima virreinal (siglos XVI-XVII), Sevilla, Junta de Andalucía, I992, pp. 42-44.

34. A Buenos Aires, entonces un lugar periférico, los coches llegaron en esas mismas fechas. Véase José Torre Revello, "Los coches en el Buenos Aires antiguo", Historia, núm. 3, 1956, pp. I6I-163.

35. Ramón María Serrera, La América de los Habsburgo (I517-1700), Sevilla, Universidad de Sevilla-Fundación Real Maestranza de Caballería, 20I I, p. 334, y, del mismo autor, "Un uso marginal de la riqueza minera indiana: la acumulación suntuaria de metales preciosos", Anuario de Estudios Americanos, núm. 34, 1977, pp. 487-515. De las obras que han tratado del lujo cabe citar José Durand, "El lujo indiano", Historia Mexicana, vol. VI, núm. I, I956, pp. 59-74; y Pilar Gonzalbo Aizpuru, "De la penuria y el lujo en la Nueva España. Siglos XVIXVIII", Revista de Indias, vol. LVI, núm. 206, 1996, pp. 49-73.

36. Gustavo Curiel, "Ajuares domésticos. Los rituales de lo cotidiano", en Pilar Gonzalbo Aizpuru (dir.), Historia de la vida cotidiana en México, vol. II, La ciudad barroca, Antonio Rubial García (coord.), México, El Colegio de México/Fondo de Cultura Económica, 2005, pp. 8I-I08, en especial I04-Io6. Véase también Gustavo Curiel, "El efímero caudal de una joven noble. Inventario y aprecio de los bienes de la marquesa dońa Teresa Francisca María de Guadalupe Retes Paz Vera (ciudad de México, I695)", Anales del Museo de América, núm. 8, 2000 , pp. 65-Ior. El carácter ostentoso del carruaje se ha mantenido en Sevilla hasta la actualidad, acerca de lo cual remitimos a Rafael Atienza, "El carruaje como objeto de ostentación social”, Minervae Baeticae, núm. 34, 2006, pp. 197-202. 


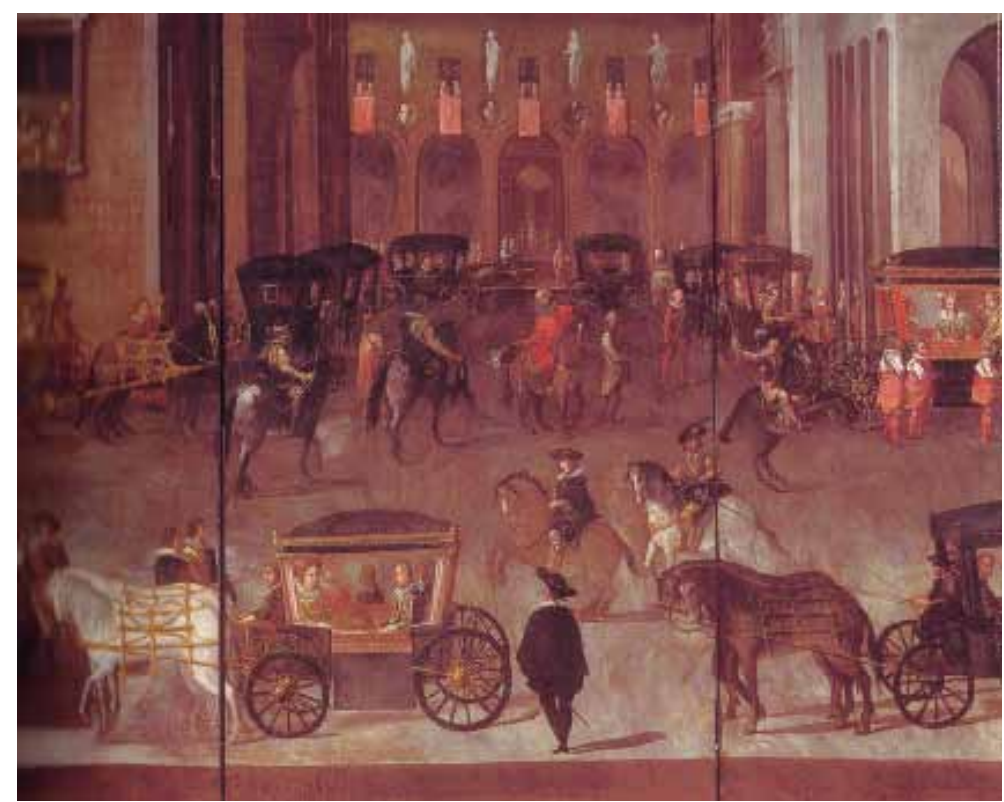

5. Carruajes, siglo xvir. Colección Museo Soumaya. Fundación Carlos Slim, A.C./Ciudad de México.

\section{El surgimiento del gremio de carroceros de la ciudad de México en 1706}

La nueva realidad que hemos descrito explica que el virrey duque de Alburquerque, el 2I de febrero de 1706, decretase la separación del gremio de carpinteros de la ciudad de México "del oficio de carroceros" (fig. 6). ${ }^{37}$

Este dato resulta muy revelador, en primer lugar, por indicar que a estos profesionales se les llamaba carroceros, a diferencia de lo que ocurría en España, donde su denominación habitual era la de maestros de hacer coches. Mucho más interesante resulta que tal referencia prueba que el origen del oficio de carrocero se produjo en la Nueva Espańa como una especialidad de la carpintería, igual que acababa de ocurrir en Sevilla. En efecto, el gremio hispalense de maestros de hacer coches surgió en 1703 tras un áspero pleito con el gremio de correeros. Hasta entonces las ordenanzas de la ciudad estable-

37. Archivo Histórico del Distrito Federal (en adelante AHDF), Sección Ayuntamiento, leg. 38I, exp. 4.I, f. I. 
6. Taller de carrocería, L'Encyclopédie de Diderot y D’Alambert, París, s.e., I75I-I772. ARTFL. Encyclopédie Proyect, University of Chicago.

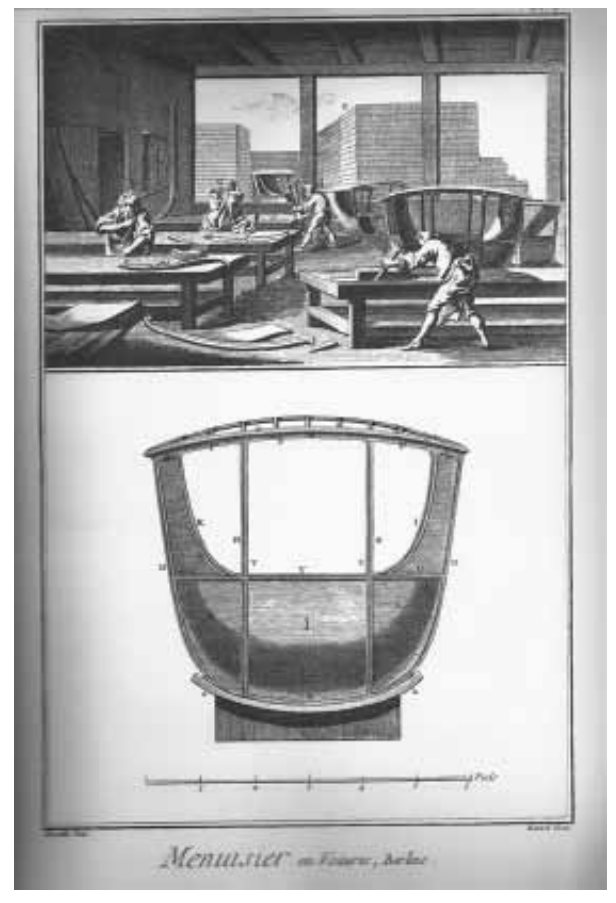

cían que correspondía a los carpinteros de lo prieto realizar, entre otras cosas, "carretas". ${ }^{8}$ No obstante, en 1690 los carpinteros de lo prieto pidieron al ayuntamiento la creación de un gremio de maestros de hacer coches con las mismas ordenanzas que el de Madrid. Esgrimían que la falta de regulación ocasionaba "grave daño, perjuicio y fraude en las obras que se hacían". Sin embargo, ello fue contestado por los correeros, ya que su gremio "siempre había estado en posesión de hacer todo género de guarnecidos de coches", mientras que los carpinteros de lo prieto sólo se habían ocupado de "hacer las cajas de los coches y demás que toca a la madera”. De toda la farragosa prosa procesal que generó el pleito, destaca el proyecto de ordenanzas que los maestros de hacer coches sevillanos plantearon en I698. El proceso concluyó en I703, cuando fue aprobado el gremio hispalense, el cual se rigió por las ordenanzas de la capital de 
España, ya que éstas fueron aprobadas por Carlos II para Madrid y "todas las demás ciudades y villas y lugares de estos nuestros reinos y señoríos". 39

De igual forma, en la ciudad de México las ordenanzas de carpinteros de I568 establecían que los carpinteros de lo prieto, para alcanzar la maestría, habrían de saber hacer, entre otras cosas, "una carreta"..$^{40}$ Significativamente, cuando surgió el gremio de carroceros en 1706 no se rigieron por las ordenanzas madrileńas, sino por unas propias. De hecho, como veremos, la norma novohispana es muy distinta del proyecto sevillano de I698 y también —aunque no tanto- de las ordenanzas madrileñas.

En cualquier caso, la creación del gremio novohispano prueba la existencia de una tradición en la construcción de carruajes suficientemente consolidada para requerir un reconocimiento legal y una normativa y organización específicas. De igual manera, evidencia la necesidad de los carroceros de concretar el ámbito de su arte para evitar la intromisión de otros profesionales y defender sus intereses.

No debe olvidarse con relación al surgimiento del gremio la cuestión técnica. La evolución del arte de la carrocería en el siglo Xvir creó coches cada vez más complejos. ${ }^{4 \mathrm{I}}$ Ello obligaría a un mayor desarrollo técnico para el que resultaba necesaria una especialización manufacturera paralela, lo cual también influiría en la separación en 1703 del gremio de carpinteros de la ciudad de México de escultores y ensambladores. ${ }^{42}$

39. Véase Álvaro Recio Mir, "La construcción de coches en la Sevilla barroca: confluencias artísticas y rivalidades profesionales", en Arte, arquitectura y urbanismo. I. Congreso Internacional Andalucía Barroca. Actas, Sevilla, Consejería de Cultura de la Junta de Andalucía, 2009, pp. $405-416$.

40. Barrio Lorenzot, op. cit., p. 85 .

4I. Sobre ello remitimos a la bibliografía citada en la primera nota de este trabajo.

42. Véanse Barrio Lorenzot, op. cit., pp. 87-89; Ernesto Chinchilla Aguilar, "Ordenanzas de escultores, carpinteros, entalladores y violeros de la ciudad de México", Antropología e Historia de Guatemala, vol. V, núm. I, 1953, pp. 29-52; Guillermo Tovar de Teresa, "Consideraciones sobre retablos, gremios y artífices de la Nueva España en los siglos XVII y Xviı", Historia Mexicana, vol. xxxıv, núm. I, I984, pp. 5-40; Guillermo Tovar de Teresa, Índice de documentos relativos a Juan Correa, maestro pintor, existentes en el archivo de notarias de la ciudad de México precedido por consideraciones sobre retablos, gremios y artífices de la Nueva España en los siglos XVII y XVIII, México, El Equilibrista, I988, pp. 6 y ss.; Rogelio Ruiz Gomar, "El gremio de escultores y entalladores en la Nueva España", en Imaginería virreinal. Memorias de un seminario, México, Instituto Nacional de Antropología e Historia, 1990, pp. 27-45, y María del Consuelo Maquívar, "Los escultores novohispanos y sus ordenanzas", Historias, núm. 53, 2002, pp. 89-99. 
No obstante, cabría suponer también que la temprana aparición del gremio novohispano podría obedecer, además de a razones técnicas y laborales, a que en América el sistema gremial se constituyó en medio fundamental de articulación social. ${ }^{43}$

La propia fecha, I706, resulta en sí misma significativa, ya que prueba un desarrollo temporal paralelo al metropolitano. En España el primer gremio comprobado fue el de Madrid, con ordenanzas aprobadas en I666, aunque sufrieron una adición en I692. Empero, tales normas señalan que están basadas en "la ordenanza de los maestros cocheros de Toledo", lo que prueba la existencia de una normativa anterior desconocida. ${ }^{44}$ Incluso cabría aludir a la creación del gremio inglés en 1677.45

La cronología de la creación del gremio de la ciudad de México y de sus ordenanzas rompe dos temas habituales en la historiografía hispanoamericana. El primero, que no es posible trasladar al ámbito americano las categorías histórico-artísticas europeas, que en este caso es el único método de análisis posible. El segundo, que los centros productivos americanos tuvieron un desfase cronológico respecto a los europeos. Todo parece indicar, como ya vimos, que el coche tuvo un desarrollo paralelo a ambos lados del Atlántico, lo que no impide atisbar particularidades americanas. ${ }^{46}$

43. A este respecto y con carácter general, véase Ramón Gutiérrez (coord.), Pintura, escultura y artes útiles en Iberoamérica, I500-1585, Madrid, Cátedra, I995, pp. 25-50.

44. Ángel López Castán, "La construcción de carruajes y el gremio de maestros de coches en la Corte durante el siglo xviı", Boletín del Museo e Instituto Camón Aznar, núm. 23, I986, pp. 99-II5. También sabemos que en Granada ya en i669 se planteó la separación de los maestros de hacer coches del gremio de carpinteros. Véase Lázaro Gila Medina, Maestros de carpintería en la Granada moderna según los escribanos de la ciudad, Granada, Colegio Notarial de Granada, 2008, p. 365.

45. Historia del carruaje en España, op. cit., p. I90.

46. El aludido lujo de sus carruajes parece ser una de ellas, igual que el empleo de ciertas técnicas y materiales, como el enconchado y el maque. De enconchado se citan ejemplos en Francisco Javier Hernández, Carruajes, sillas, jaeces..., México, Ediciones de Arte, 1948, p. 3, y de maque, seguramente de procedencia china, en Gustavo Curiel, "Cuatro inventarios de bienes de particulares del Real y Minas de San José del Parral. Siglo xviı", en Actas del Segundo Congreso de Historia Regional Comparada, México, Universidad Autónoma de Ciudad Juárez, 1990, pp. 249-279, véase en concreto la 253 in fine. Vinculado con lo anterior está el uso habitual de plata en arneses y guarniciones, aludido en María Jesús Sanz, "El arte de la platería en el suroeste de los Estados Unidos. Formación e influencias", Anales del Museo de América, núm. 13, 2005, pp. 249-272. De los aspectos técnicos de los coches nos ocuparemos en otra ocasión. 
No obstante, la realidad novohispana es susceptible de ser comparada, además de con la metropolitana, con lo ocurrido en la otra capital virreinal, Lima. En ésta, el gremio de carroceros era subalterno del de carpinteros, aunque contaba con un maestro mayor y con veedores propios, e incluso estaba regulado por ordenanzas particulares, aprobadas por el cabildo de Lima en I575. Significativamente, estas normas, que no conocemos, se guiaban "por la horden" de las de Sevilla. ${ }^{47}$

Aunque, como señalamos, el gremio sevillano nació en $\mathrm{I703}$, hay indicios de la existencia de regulaciones anteriores desde el siglo xvi. ${ }^{48}$ De igual forma, en el XVII se alude a otras aún desconocidas ordenanzas de "maestros y oficiales que tienen talleres de coches". 49 En cualquier caso, la referencia limeña apoya nuestra hipótesis de la proyección de la carrocería hispalense en el ámbito americano, que debió ser de especial significación en el caso peruano debido a las intensas relaciones de la Ciudad de los Reyes y la capital bética a finales del siglo Xvi y principios del XVII.

\section{Análisis comparado de las primeras ordenanzas de carroceros de la ciudad de México (I706)}

Aunque la transcripción de las ordenanzas de los maestros carroceros de la ciudad de México de 1706 se publicó a principios del siglo xx, ${ }^{50}$ ha sido ignorada por la historiografía que se ha dedicado al estudio del coche de caballos. Sin duda, un análisis comparado de las ordenanzas con los otros textos legales

47. Lohmann Villena, op. cit., p. I43.

48. Cuestión, aún por estudiar, apuntada en Antonio Miguel Bernal et al., "Sevilla: de los gremios a la industrialización”, Estudios de Historia Social, núm. 5-6, 1978, pp. 7-307, donde junto a la fundación del gremio sevillano al que nos venimos refiriendo se alude a otro de "fabricantes de coches". Véase la p. 84.

49. Vicente Romero Muñoz, Los gremios de Sevilla, Sevilla, Padilla, 200I, p. 22.

50. Barrio Lorenzot, op. cit., pp. 89-92. A pesar de tal publicación, en adelante, cuando aludamos a estas ordenanzas, seguiremos nuestra propia transcripción a partir de su fuente original, AHdF, Sección Ayuntamiento, leg. 38I, exp. 4.I, ff. I-4, ya que la transcripción publicada no abarca la totalidad del documento y, en ocasiones, no coincide con el que nosotros hemos consultado, suponemos que debido a que la fuente usada por Barrio Lorenzot era una copia. Una parte de las ordenanzas publicadas por Barrio Lorenzot fue recogida en Francisco Santiago Cruz, Las artes y los gremios en la Nueva España, México, Jus, I960, pp. II5 y II6. 
ya referidos — las madrileñas de I666-I692 y el proyecto sevillano de I698puede arrojar mucha luz sobre la carrocería de todo el mundo hispánico. ${ }^{\text {I }}$

La norma en cuestión fue aprobada por el ayuntamiento de la ciudad de México el 24 de mayo de i706. El i6 de junio, "en la plaza mayor de esta ciudad y portal de los mercaderes por voz de Diego Velázquez, que hace oficio de pregonero público, repregonaron las ordenanzas de los maestros carroceros”. Por fin, el día siguiente las confirmó el virrey don Francisco Fernández de la Cueva, X duque de Alburquerque.52

Está articulada la norma en 17 ordenanzas, siendo la primera relativa a la elección, a principios de cada año, de los dos veedores del gremio, que se llevaría a cabo, "como lo hacen los demás gremios", en el ayuntamiento de México, con la asistencia obligatoria de todos los maestros y estando penada su ausencia con Io pesos de oro, los cuales se aplicarían a la "cámara, juez y gastos del gremio".

En el caso madrileño, la elección de los veedores, a los que significativamente se llaman "veedores y examinadores", es tratada de forma similar en el punto tercero de un total de 16.53 Por su parte, el proyecto de ordenanzas de Sevilla de I698 - menos sistemático que el madrileño y el novohispanoapunta que también cada año, el segundo domingo de junio, habrían de reunirse todos los maestros de hacer coches para elegir dos veedores, "los más hábiles y capaces que hubiere". 54

La segunda ordenanza novohispana especifica que sólo los maestros examinados podrían abrir "tienda pública" u "obrador", siendo penada con el cie-

5I. Este método de análisis ya fue apuntado en Manuel Carrera Stampa, La organización gremial en Nueva España. I52I-I86I, México, Cámara Nacional de la Industria de Transformación, I954, p. 246, n. 78, y seguido en Maquívar, op. cit. Sobre el análisis de la normativa gremial remitimos también a Raúl Carrancá y Trujillo, "Las ordenanzas de gremios de Nueva España", separata de Crisol, ı932; Richard Konetzke, "Las ordenanzas de gremios como documentos para la historia social de Hispanoamérica durante la época colonial", Revista Internacional de Sociología, vol. 5, núm. I8, I947, pp. 42 I-449; y Guillermo Redondo Veintemillas, "Las ordenanzas gremiales: vías metodológicas para su estudio", en Metodología en la investigación cientifica sobre fuentes aragonesas, Universidad de Zaragoza, 1985, pp. I33-I64.

52. AHDF, Sección Ayuntamiento, leg. 381, exp. 4.I, f. 4.

53. Para todo lo relativo a las ordenanzas madrileńas remitimos a López Castán, op. cit., pp. II2-II5.

54. El proyecto sevillano es muy complejo y de marcado carácter técnico, pero hace menos referencias a la organización profesional. Véase Recio Mir, "La construcción de coches en la Sevilla barroca...”, op. cit., pp. 408 y 409. Sólo cuando tratemos algún asunto no referido en dicho trabajo, como en este caso, remitiremos a la fuente original, Archivo Municipal de Sevilla (en adelante AMs), Sección $V$, siglo XVIII, vol. 250, h. I309, doc. 9, f. I8. 
rre y 20 pesos la contravención de esta norma. No obstante, añadía que como muchos oficiales deseosos de abrir tienda no podían costearse el derecho de examen,55 "siguiéndoles notable atraso", se les permitía hacerlo avisando de ello a los veedores y examinándose en seis meses "peremptorios". Si no superasen el examen, habrían de cerrar sus tiendas.

Las ordenanzas de Madrid, en su primer punto, sólo permitían abrir tienda a los oficiales examinados, con "carta de examen autorizada por el escribano que para ello nombrase el gremio". Igualmente, el proyecto sevillano no establecía excepciones a la habitual norma gremial por la que sólo los maestros examinados podían abrir tienda. Los casos españoles son, por tanto, en este sentido más estrictos que el novohispano.

En tercer lugar, las ordenanzas de la ciudad de México señalan que quien se examinase tenía que haber aprendido el oficio "con escriptura", con la excepción de los hijos de los maestros. Quien no tuviera la referida certificación tendría que demostrar que había aprendido el oficio y que había trabajado algún tiempo en el taller de un veedor.

Las ordenanzas de Madrid — punto cuarto- también exigían a los aspirantes a maestros certificar su formación como aprendices y oficiales al menos durante seis años. Por su parte, el proyecto de ordenanzas sevillano, también en esto más específico, indicaba que la escritura debería probar que el aspirante había sido cinco ańos aprendiz y tres oficial. La normativa novohispana volvía a ser algo más laxa en esta cuestión.

En cuarto lugar, las ordenanzas novohispanas indican que el oficial que trabajase en una casa particular perdería la obra y las herramientas con que la hiciere, todo lo cual sería vendido para aplicarlo de nuevo a la "cámara, juez y gastos del gremio". De similar tenor son las ordenanzas madrileñas en su segundo apartado, mientras que el proyecto sevillano señala sólo la posibilidad de trabajar en tiendas o cocheras.

La quinta ordenanza novohispana especifica que "al oficio de carrocero toca hacer coches, forlones, sillas bolantes, literas y todo aquello que mira a andar en animales cuadrúpedos". La cuestión tipológica es una de las más complejas de la carrocería. El tenor de la norma no sólo alude a los tipos básicos del momento, sino que añade todos los ingenios tirados por cuadrúpedos. Para entender este último detalle hay que traer a colación la norma madrileña y el

55. En la Nueva España generalmente los oficiales pagaban para examinarse dos pesos a cada veedor y otros dos a la cofradía. Véase Barrio Lorenzot, op. cit., p. IV. 
proyecto sevillano. La primera, en su primer punto, alude a "carrozas, literas, coches, estufas o calesas y todos los demás que se inventaren de nuevo", mientras que el segundo - de nuevo muy preciso- a

una carroza de media vuelta a la moda, una carroza de pisones, con medias puertas, una carroza para una mula, una carroza con dos vigas, una carroza entrepańada, una carroza con puertas enteras, una estufa con medias puertas, una estufa de caballetes con puertas y marcos corredizos, una estufa ochavada, un carrocín, una calesa a la moda, un coche redondo de rúa, un coche de camino redondo, una calesa de camino, una galera de campaña, un carro triunfante y un juego con los cabezales a dos literas. ${ }^{56}$

Ello explica que las ordenanzas de la ciudad de México no sólo incluían en el ámbito de los carroceros futuros modelos de coches no referidos específicamente en ellas, como dicen las madrileñas, sino que también debió aludir —al referirse a "todo aquello que mira a andar en animales cuadrúpedos" - a los carros triunfales, específicamente señalados en el proyecto sevillano, y protagonistas de la fiesta barroca.

Los tipos citados en las normas madrileńa y sevillana serían los que ruaban por ambas ciudades. La evolución del coche desde sus orígenes en el siglo XVI fue tan formidable que a principios del XVIII sus tipologías se habían diversificado de tal forma que no resulta fácil saber a qué se refiere cada una de las denominaciones referidas. ${ }^{57}$

No creemos que el hecho de que las ordenanzas novohispanas mencionen pocos tipos de coches pueda llevar a pensar que en el virreinato no existiese la misma variedad que en España. Por el contrario, suponemos que el desarrollo del carruaje debió ser similar en ambas, en particular por el carácter cortesano de la ciudad de México y por el uso de coches en las entradas solemnes de virreyes y arzobispos..$^{8}$

56. Véase n. 54.

57. Sobre las tipologías, que aquí apenas mencionamos, véase la bibliografía de la nota I.

58. Que la variedad de coches fue mayor que la apuntada en la norma se evidencia, por ejemplo, en que ya a finales del siglo Xviı se usaban en la ciudad de México coches de dos plazas, como se seńala en Giovanni Francesco Gemelli Careri, Viaje a la Nueva España, Francisca Perujo (ed.), México, Universidad Nacional Autónoma de México, I983, p. 77. Suponemos que con ello se estaba aludiendo a los cupés, los cuales derivan de la berlina, por lo que cremos que ambos tipos ya eran conocidos en la capital de la Nueva España aunque no se citen en las ordenanzas de los carroceros. 
La sexta ordenanza novohispana indica que el oficial que se examinase para alcanzar la maestría tendría que "dar entera noticia de todo aquello de lo que se le preguntare, así en la demostración como en la ejecución”. De ello parece desprenderse que los exámenes eran tanto teóricos como prácticos.

Las ordenanzas madrileñas — puntos quinto y sexto — no son demasiado específicas sobre este asunto de la obra maestra. En principio, señalan varios tipos de coches que se habrían de ejecutar en los exámenes: carrozas de media vuelta, galzas de camino, estufas de caballete o berlinas. No obstante, reconocen que hacerlas "hubiese sido no corto dispendio para los examinados", por lo que plantean la posibilidad de que los veedores "hagan varias preguntas a los examinandos, en razón de las baquetas y maderas que entran en la composición de qualquier carruaje".

El proyecto sevillano de ordenanzas volvía a ser más específico en esta cuestión, ya que seńalaba que los examinadores mandarían a los oficiales "hazer la pieza que quisieran y preguntándoles por las demás y dando razón bastante se le aprovara". 59

Cabe suponer por todo lo anterior que los exámenes combinarían una parte teórica y otra práctica, en concreto, la ejecución de una pieza significativa de algún tipo de carruaje, ya que hacerlo completo habría sido muy costoso.

En séptimo lugar, las ordenanzas novohispanas especifican que quienes se dedicasen a alquilar coches y forlones no los podrían "aderesar" en sus casas, "salvo siendo maestros", estableciendo una pena de 25 reales a los infractores. Aunque las ordenanzas madrileñas y las sevillanas abordaban la cuestión, no lo hacían como las americanas con relación al alquiler de coches. Cabe inferir de ello que tal actividad era habitual en la Nueva Espańa y que estaba más extendida que en la metrópoli a principios del siglo xvirI. Sin embargo, las primeras normas sobre alquiler de coches en el virreinato no fueron promulgadas hasta 1793, dándose la circunstancia de que se tienen por pioneras en el Nuevo Mundo. ${ }^{6}$ Sin duda, ello muestra la generalización del uso de vehículos y las formas de articular tal necesidad en la sociedad barroca virreinal, donde, al igual que España, se convirtió en una auténtica patología social. ${ }^{6 r}$

59. AMs, Sección $V$, siglo XVIII, vol. 250, h. I309, doc. 9, f. I I.

6o. Esta regulación es estudiada en Serrera, op. cit., pp. 328 y ss.

6I. Prueba de ello es el fenómeno del "enconchado", asunto tratado en López Álvarez, "Los vehículos representativos en la configuración de la corte virreinal...”, op. cit. 
La octava norma novohispana indica la función de los veedores: visitar las tiendas y las obras que en ellas hubiere. Si éstas no se atenían a lo dictado en las ordenanzas, las harían rectificar. De lo contrario, las multarían con 25 pesos. ${ }^{62}$

De similar tenor son la tercera ordenanza del gremio de Madrid y el proyecto sevillano. Éste encomendaba a los veedores, además de examinar a los oficiales, visitar "las obras y tiendas de los demás de su oficio reconociendo si se cumple con las ordenanzas en todo lo que toca a maderas y clavasón". ${ }^{63}$

La novena ordenanza novohispana dice "que los guarnicioneros, ni otros oficios, no puedan ajustar en sus casas ni en las de particulares, encerados para coches, forlones o sillas volantes, ni los demás que pertenece a carrocería ni guarnecer las caxas ni vestirlas", so pena de 20 pesos. Sin duda, debió resultar esencial la competencia de los correeros, a los que correspondía el habitual recubrimiento de cuero de las cajas de los coches. Por su parte, la alusión a los revestimientos de su interior, pensamos, tendría que ver con posibles rivalidades con los tapiceros.

Las ordenanzas de Madrid nada dicen al respecto. No obstante, el proyecto sevillano, que precisamente surgió por la rivalidad con los correeros, señala un interesante dato: los correros sevillanos se opusieron a que se aplicase en su ciudad la norma madrileńa sobre carrocería debido a que en la capital de España no existía la separación entre ambas profesiones que sí se daba en Sevilla, lo que explica el aludido silencio de la norma madrileña. En la Nueva Espańa, que sí contaba con gremio de correeros, también debieron surgir conflictos profesionales, lo que explicaría la mención explícita de tal rivalidad en las ordenanzas de los carroceros.

El punto décimo de las ordenanzas novohispanas indica que sólo los maestros carroceros podían tasar y apreciar coches, so pena, en caso contrario, de 25 pesos. Quizá ello aluda a un incipiente mercado de coches de segunda mano. En cualquier caso, nada dicen al respecto ni la norma madrileńa ni el proyecto sevillano.

El undécimo punto especifica que si algún maestro con tienda quebrase o la cerrase por alzamiento de bienes, no podría abrirla de nuevo a menos que

62. AHDF, Sección Ayuntamiento, leg. 38I, exp. 4.I, f. 2. En este caso, el documento que hemos consultado no coincide con la transcripción publicada, que dice que los veedores supervisarían los coches "y no hallándolas como deven ser, con las maderas bien acondicionadas y perfectamente hechas las obras públicamente las quemen y demás multa al maestro a quien se hallare de veinte y cinco pesos". Barrio Lorenzot, op. cit., pp. 90-9I.

63. AMs, Sección V, siglo XVIII, vol. 250, h. I309, doc. 9, f. I8. 
diese a los veedores una fianza de 2000 pesos. Tampoco nada dicen de ello las normas metropolitanas, que en este sentido son menos específicas y rigurosas.

La siguiente ordenanza novohispana dice:

los veedores tengan cuidado que cuando alguno se examinase se den los seis pesos que siempre ha sido costumbre dar para el culto del santo ángel que el gremio saca en la procesión del Santo Entierro que el Viernes Santo sale del convento real de Santo Domingo, los cobrare y tenga en su poder con las multas y que el día de la elección de veedores los viejos pasen las cuentas a los nuevos. ${ }^{64}$

Ello resulta de sumo interés, pues demuestra que la actividad carrocera estaba consolidada antes de surgir el gremio. Asimismo, es significativa la alusión, más que a una hermandad, a una devoción. Sabemos que en Guadalajara, por ejemplo, también en la procesión del Santo Entierro participaban los gremios, representados por imágenes de los santos ángeles, cada uno de los cuales portaba un elemento de la Pasión. ${ }^{65}$

En Madrid los maestros de coches, igual que los demás oficios de la madera, pertenecían a la hermandad de San José. Por su parte, el proyecto sevillano planteaba la posibilidad de que en el futuro surgiese una hermandad, sin especificar su advocación.

El decimotercer punto de las ordenanzas novohispanas obligaba a los veedores a tener un libro en el cual registrarían los ingresos del derecho de examen y las multas, que se dedicarían al culto del santo ángel. Las cuentas habrían de ser aprobadas "con claridad" y el correspondiente libro se transmitiría de unos veedores a otros. No son tan rigurosas las normas metropolitanas, que nada dicen de tal contabilidad.

La decimocuarta ordenanza novohispana informa que

Joseph Maldonado, vezino de esta ciudad, por la devoción que ha tenido y tiene al santo ángel del gremio, movido de buen celo y charidad ha tenido y guardado en su poder con todo cuidado los bienes del santo ángel y en agradecimiento que le tiene el gremio por el celo y cuidado pide que los dichos bienes que a el presente ay y

64. AHDF, Sección Ayuntamiento, leg. 38I, exp. 4.I, ff. 2v. y 3.

65. María Estela Guevara Zárraga, Gremios novogalaicos, Universidad de Guadalajara (México), 1993, p. I3. 
hubiere se aumentasen en adelante mientras viviere el susodicho paren en su poder teniendo razón los veedores de los que son.

A ello añadía que, a su muerte, pasarían tales bienes a los veedores. ${ }^{66}$

Ello, que enlaza con lo tratado dos puntos atrás, prueba que el gremio no hacía más que institucionalizar una realidad preexistente y que, en concreto, en la cuestión devocional tal proceso no concluiría hasta la muerte del referido devoto. Nada sabemos de él, pero la forma de aludirlo nos hace sospechar que no sería carrocero.

El punto decimoquinto indica que si algún maestro no pudiese pagar el local del taller y se le ofreciese trabajar en una casa particular no lo hiciese, so pena de 25 pesos. Lo que se establecía en ese caso era que el referido maestro habría de trabajar en el taller de otro maestro, el cual tenía que informar de ello a los veedores para que recaudasen la correspondiente alcabala, ya que si no lo notificaba la debería pagar él.

El punto dos de las ordenanzas de Madrid era similar, mientras que el proyecto sevillano nada dice al respecto. El cobro de los referidos impuestos era una de las formas más evidentes y efectivas de control oficial de la producción artística y artesanal.

La penúltima ordenanza novohispana prohibía vender los elementos metálicos de los coches viejos. Si así se hacía, el vendedor los perdería y pagaría io pesos de multa. Ello apunta la existencia de un mercado de desguace, quizá debido a una constante renovación del parque móvil, de lo que nada dicen las normas metropolitanas.

La decimoséptima y última ordenanza de la ciudad de México señala que la compra de madera por los carroceros estaba sujeta a las ordenanzas de regatones de madera y que habrían de hacerla sólo en la cantidad necesaria, "sin que su oficio les sirva de pretexto para regatonear maderas". No aluden a ello las normas madrileńa y sevillana. Posiblemente el control de la madera, como material estratégico, sería mayor en el virreinato que en la metrópoli, lo que enlaza con el control sobre el hierro ya citado. ${ }^{67}$ Además, esta ordenanza apunta una nueva rivalidad profesional.

66. AHDF, Sección Ayuntamiento, leg. 38I, exp. 4.I, f. 3v.

67. Sobre el control de la madera en México véase José María Lorenzo Macías, "La aplicación de las ordenanzas del gremio de carpinteros en el siglo xvi. El caso de Juan Gordillo contra su gremio", Anales del Instituto de Investigaciones Estéticas, vol. xxv, núm. 83, otońo de 2003, pp. I53-177. 
Conviene empezar el análisis de conjunto de las ordenanzas novohispanas planteando una pregunta: ¿por qué, al igual que ocurrió en Sevilla en I703, en la ciudad de México no se aplicaron las ordenanzas de Madrid, cuyo ámbito eran "todas las demás ciudades y villas y lugares de estos nuestros reinos y señoríos”? Quizá, más que esa pregunta, habría que formular otra: ¿por qué las de Madrid se aplicaron en Sevilla cuando este tipo de normas solía tener carácter local? No tenemos todavía respuesta para tales cuestiones. Probablemente otras fuentes aún por analizar darían luz al respecto — registros de exámenes, listados de maestros o actas del gremio. En cualquier caso, junto a las ordenanzas novohispanas de carroceros, conocemos otras en España distintas a las madrileńas, como las de Valencia de $1753 .{ }^{68}$ Seguramente, a la postre, las peculiaridades locales acabaron triunfando sobre el carácter general de las normas de Madrid.

Como texto jurídico, las ordenanzas novohispanas de 1706 no destacan por una particular perfección técnica, ni siquiera siguen un orden lógico. Por ello cabe suponer que serían redactadas por los propios carroceros, quienes las presentarían al ayuntamiento de la ciudad para su aprobación y luego al virrey para su ratificación. Su relativa simplicidad y cierto carácter laxo ya aludido parecen corresponder a un estado embrionario de la profesión. En cualquier caso, atienden los aspectos habituales de estas normas: derecho civil y penal y la cuestión religiosa del gremio. En concreto, las ordenanzas novohispanas tratan del funcionamiento del gremio, de la calificación y examen de los maestros, del ejercicio profesional evitando la rivalidad de otros gremios y profesiones, del control de calidad de las obras por los veedores y de la cofradía.

Pero estas ordenanzas no sólo son significativas por lo que dicen, también lo son por lo que callan. Así, no hacen alusión a ningún tipo de segregación racial, cuestión de la que tratarían con posterioridad. ${ }^{69}$ Ello podría indicar que, en un primer momento, la carrocería sería ejercida fundamentalmente por españoles y criollos, por lo que no tuvieron que reservarse esta profesión, como sí ocurrió con otras. ${ }^{70}$

De igual modo, extraña que no aludan a los tipos de maderas usadas en

68. Carmen Rodrigo Zarzosa, Carruajes del palacio de los marqueses de Dos Aguas. Museo Nacional de Cerámica. Catálogo, Valencia, Museo Nacional de Cerámica, I991, pp. I29-I34.

69. De las posteriores reformas de las ordenanzas que venimos analizando nos ocuparemos en otra ocasión.

70. Véase Manuel Carrera Stampa, Los gremios mexicanos. La organización gremial en Nueva España, I52I-I86I, México, Edoapsa, 1954, pp. 223 y ss. 
los coches. En ello son muy descriptivas las normas madrileña y sevillana. Así, la primera señala que las cajas, tijeras, lanzas, los cabezales, ejes, tejados y las vigas serían de álamo negro; los radios de las ruedas de encina, y las puertas, los marcos y pesebrones de nogal o álamo blanco. El proyecto sevillano, aún más específico, dice que las cajas habrían de ser de álamo blanco; sus pesebrones de álamo blanco o nogal; las puertas y sus marcos de álamo negro; las vigas de álamo negro o fresno; las tijeras, los cabezales, ejes, balancines y las lanzas de álamo negro; las arquillas de pino o de álamo blanco; los tejados de álamo blanco y las varas de las literas de álamo negro o fresno.

Asimismo, cabría plantear si la sistematización profesional que supuso la creación del gremio y sus ordenanzas repercutió en la calidad de los coches novohispanos. Al haberse perdido éstos, de los que apenas quedan referencias literarias e iconográficas, resulta imposible probarlo. No obstante, cabe suponer que así sería, ya que ésa era una de las intenciones del gremio. Sin embargo, no podemos olvidar que las ordenanzas indicaban cómo debía funcionar el gremio, no cómo lo hizo en realidad.

Otra cuestión es la posible influencia del gremio de la ciudad de México y sus ordenanzas en otros lugares del virreinato. Sabemos al respecto que en Puebla ya había gremio de carroceros desde al menos los años treinta del siglo xviII. ${ }^{7 \mathrm{I}}$ Hay vagas noticias acerca de la existencia de carreteros y carroceros en la ciudad de Guatemala en I773. Se da la circunstancia de que en el entorno de ella se produjo una especialización laboral, destacando la localidad de San Luis de las Carretas, "así llamada porque sus vecinos trataban de fabricar carros y guardaban los que tenía la ciudad para varios usos".72

Teniendo en cuenta que las ordenanzas del gremio de plateros de la ciudad de México se adaptaron a otros lugares del continente por real cédula del I2 de octubre de 1776, no podemos descartar — como ya de forma genérica señaló Manuel Carrera Stampa — ${ }^{73}$ la proyección de las normas del gremio de carroceros sobre ámbitos territoriales con los que la capital virreinal tenía una relación particular, como Cuba, Guatemala o Filipinas.

En cuanto a la vigencia de las ordenanzas de 1706 , hay que señalar que apenas superó el medio siglo, ya que fueron reformadas por completo a par-

7I. Agmp, Archivo Histórico, Serie de Expedientes, vol. 223, ff. I 4V y ss.

72. Héctor Samayoa Guevara, Los gremios artesanos en la ciudad de Guatemala (I524-I58I), Guatemala, Universitaria, 1962, pp. 45 y 51.

73. Carrera Stampa, op. cit., p. 243. 
tir de I763. No obstante, la creación del gremio y sus primeras normas, más que por su vigencia, hay que valorarlas por permitir la articulación de una profesión y por ser el punto culminante de la evolución de los dos primeros siglos de la carrocería novohispana. De igual modo, gremio y ordenanzas permitieron que la ciudad de México desarrollase en el siglo XVIII —clave en la historia de la carrocería - una actividad en este sentido parangonable a la de las grandes capitales españolas y europeas. No nos cabe la menor duda de que, a pesar del estado embrionario en que aún se encuentran nuestros conocimientos al respecto, no podrá ser entendida por completo la fabulosa plenitud barroca novohispana hasta que se aborde sistemáticamente el análisis de los carruajes que llenaron sus ciudades y de los carros triunfales que protagonizaron muchas de sus fiestas. ${ }^{74}$ is

74. Como ya hemos indicado, en otro momento abordaremos el estudio de la reforma de I763 y el desarrollo de la carrocería novohispana en el siglo XVIII.

* Artículo recibido el 30 de mayo de 20 I ; aceptado el I8 de noviembre de 20 I. 